\title{
SPATIAL AND TEMPORAL CHANGES OF AEROSOL OPTICAL DEPTH AND ITS DRIVING FACTORS BASED ON MODIS IN JIANGSU PROVINCE
}

\author{
C. Jiang ${ }^{1,2, *}$ Q. Xu ${ }^{1}$, Y. K. Gu ${ }^{1}$, X. Y. Qian ${ }^{1}$, J. N. He ${ }^{1}$ \\ ${ }^{1}$ Dept. of Suveying and Geoinformatics, Nanjing University of Posts and Telecommunications, Nanjing, P.R.China - (jiangc, xuq, \\ guy,hej)jiangc@njupt.edu.cn \\ ${ }^{2}$ School of Earth Sciences and Engineering, Hohai University, Nanjing, P.R.China - jiangc
}

Commission III, ICWG III/IVc

KEY WORDS: AOD, MODIS, Temporal Change, Spatial Autocorrelation, Gravity Model, Driving Factor

\begin{abstract}
:
Aerosol Optical Depth (AOD) is of great value for studying air mass and its changes. In this paper, we studied the spatial-temporal changes of AOD and its driving factors based on spatial autocorrelation model, gravity model and multiple regression analysis in Jiangsu Province from 2007 to 2016. The results showed that in terms of spatial distribution, the southern AOD value is higher, and the high-value aggregation areas are significant, while the northern AOD value is lower, but the low-value aggregation areas constantly change. The AOD gravity centers showed a clear point-like aggregation. In terms of temporal changes, the overall AOD in Jiangsu Province increased year by year in fluctuation. In terms of driving factors, the total amount of vehicles, precipitation and temperature are important factors for the growth of AOD.
\end{abstract}

\section{INTRODUCTION}

Atmospheric aerosol is a stable mixture of solid particles and liquid particles dispersed in the atmosphere, which plays a very important role in the biosphere and human health (Glasius et al., 2016). Because of its physical and chemical characteristics, atmospheric aerosol has an influence on the radiation balance of the earth's atmosphere through scattering and absorbing radiation. Aerosol Optical Depth (AOD) is one of the most basic optical characteristics of aerosol, which indicates the transmittance of the vertical gas column on the unit section (Di et al.,2016). In recent years, with the development of industry and the increase of human activities, AOD has increased rapidly and the air quality problems in China become more and more serious. More scholars have made comprehensive analyses of the air quality in the region based on the spatial-temporal data of AOD in the region (Lee et al., 2014).

At present, there are mainly two kinds of AOD data: one is an aerosol automatic ground network, such as Aerosol Robotic Network (AERONET) (Yoon et al, 2016), and the other one is to retrieve the AOD of a certain region by satellite remote sensing data, such as moderate resolution imaging spectrometer (MODIS). Though the accuracy of the ground observation network is high, it is impossible to get the AOD information of each point in the whole area due to sparse distribution of the stations. Satellite data make up for these deficiencies. It can reflect the spatial-temporal change of AOD. Many researchers found that the expected difference between AOD data obtained from the ground observation network and retrieved MODIS AOD data is in line with the accuracy requirements of the study (Salinas et al., 2009). He et al. used MODIS data at 550nm to investigate the variation in factors affecting AOD over a 3-KM grid for entire of China (He et al., 2016). MODIS products contain spatial-temporal information of AOD, which has become one of the effective means to monitor the distribution of AOD. However, most of the researches on AOD are based on the traditional methods of analysis, and the methods about spatial correlation within the region are less used.

Based on MODIS AOD data of Jiangsu Province, we studied the spatial-temporal change of AOD, and explored the relationship between the spatial-temporal changes of AOD and human activity.

\section{MATERIALS AND METHODS}

\subsection{Study Areas and Data Sources}

2.1.1 Study Areas: Jiangsu Province is the study area $\left(30^{\circ}\right.$ $45^{\prime}-35^{\circ} 20^{\prime} \mathrm{N}, 116^{\circ} 18^{\prime}-121^{\circ} 57^{\prime} \mathrm{E}$ ), which is located in Eastern China and covers a total area of $107,200 \mathrm{~km}^{2}$ with plain area of $70,000 \mathrm{~km}^{2}$. Jiangsu Province geographically across the north and south of China, and its vegetation and climate are concurrently with the characteristics of the southern China and the northern China.

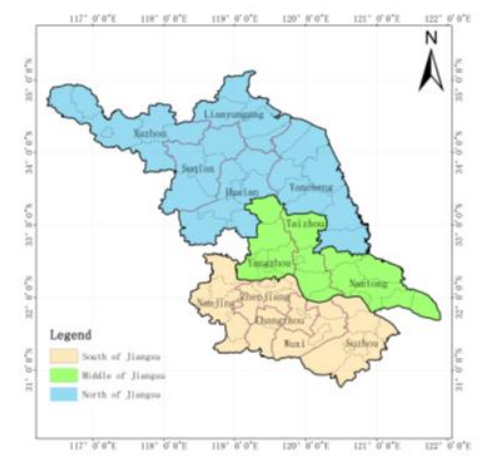

Figure 1. Location of Jiangsu Province

\footnotetext{
* Corresponding author
} 
2.1.2 Data Sources: MODIS is an important sensor mounted on the morning star Terra and the afternoon star Aqua. The MODIS image has 36 wavelengths, with the wavelength range of $0.4 \mu \mathrm{m}-14.5 \mu \mathrm{m}$ (Chang et al., 2017). Dark pixel method is a common inversion method for AOD. It uses the spectral data of MODIS at wavelengths of $0.65,0.86,0.47,0.55,1.24,1.64 \mu \mathrm{m}$ (Taneja et al.,2016). MOD04_3K is a Level 2 aerosol product released by NASA, whose resolution is $3 \mathrm{~km}$. It can be used to extract aerosol and optical properties and mass concentrations in the global marine and terrestrial environment (Xu et al.,2011) In this paper, the MOD04_3K data of Jiangsu province from January 1, 2007 to December 31, 2016 were obtained from the NASA website (https://ladsweb.modaps.eosdis.nasa.gov/), with a total of about 12000 images. We selected 8034 images with obvious features after data preprocessing including removing cloud operation,

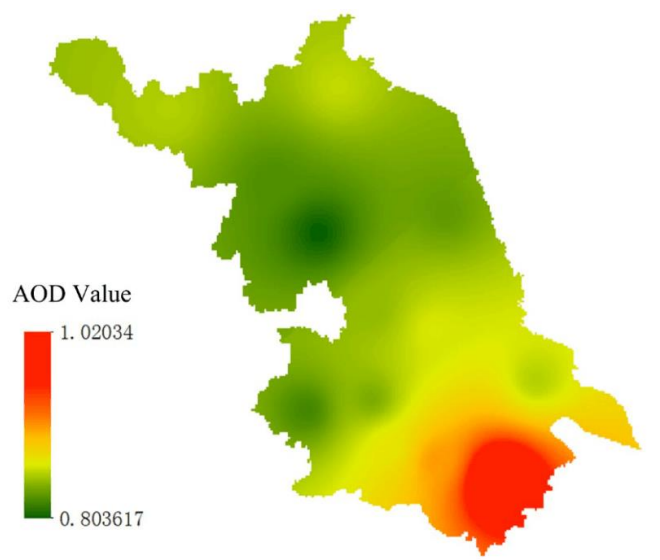

Figure 2. Spatial distribution of the mean of AOD in Jiangsu Province from 2007 to 2016

In this paper, we constructed the indicator system for AOD driving factors, including meteorological indicators, environmental pollution indicators and socio-economic indicators (Table 1). The related data came from National meteorological scientific data sharing service platform (http://data.cma.cn/), and other data came from Jiangsu Statistical Yearbook (http://tj.jiangsu.gov.cn/).

\begin{tabular}{|c|c|}
\hline Indicator & Driving Factors(Abbreviation) \\
\hline \multirow{3}{*}{$\begin{array}{l}\text { Meteorological } \\
\text { Indicators }\end{array}$} & Temperature (TEM) \\
\hline & Precipitation (PRE) \\
\hline & Wind Power (WIND) \\
\hline Environmental & Sulfur Dioxide Emission (SOX) \\
\hline \multirow[t]{2}{*}{ Pollution Indicators } & Nitrogen Oxide Emission (NOX) \\
\hline & Smoke Emission (SMO) \\
\hline \multirow{6}{*}{$\begin{array}{l}\text { Ssocio-economic } \\
\text { Indicators }\end{array}$} & Population Density (POP) \\
\hline & $\begin{array}{c}\text { The Number of Civilian Vehicles } \\
\text { (VEH) }\end{array}$ \\
\hline & Gross product of primary industry \\
\hline & (GPPI) \\
\hline & Gross product of secondary \\
\hline & $\begin{array}{c}\text { industry (GPSI) } \\
\text { Area of Gardens and Greenland } \\
\text { (GREEN) }\end{array}$ \\
\hline
\end{tabular}

Table 1. Indicators System of AOD Driving factor

\subsection{Methodology}

2.2.1 Spatial Autocorrelation: The proximity of geographic space often produces close and network effects, so the spatial autocorrelation often appears between the observation units. Spatial autocorrelation can be divided into global spatial autocorrelation and local spatial autocorrelation. We used global spatial autocorrelation to study the spatial distribution of AOD in Jiangsu Province. Moran'I is an important index, which is defined as follows:

$$
M I=\frac{\sum_{i=1}^{N} \sum_{j=1}^{N} w_{i j}\left(X_{i}-\bar{X}\right)\left(X_{j}-\bar{X}\right)}{S^{2} \sum_{i=1}^{N} \sum_{j=1}^{N} w_{i j}}
$$

where $N=$ the number of the city in Jiangsu Province

$$
\begin{aligned}
X_{i} & =\text { the annual mean value of the AOD in } \mathrm{i}-\mathrm{th} \text { area } \\
w_{i j} & =\text { the adjacency relationship between city-i and city- } \mathrm{j}
\end{aligned}
$$

" 1 " indicates adjacency, and " 0 " indicates non-adjacency. In the Moran'I interval of $(-1,1)$, a value of Moran'I greater than 0 indicates that the region is positively spatially correlated, and conversely, indicates a negative spatial correlation. The more the absolute value is closer to 1 , the stronger the correlation is.

2.2.2 Gravity Model for AOD: The concept of AOD gravity center transfer is inspired by the theory of classical mechanics (Pitońák et al.,2017). It represents the point of action that the AOD value is balanced in all directions in the study area. The movement of gravity center can objectively reflect the spatialtemporal changes of AOD. The gravity center is defined as follows (Crippa et al.,2016):

$$
L A_{i}=\frac{\sum_{j=1}^{n} p_{i j} \cdot l a_{j}}{\sum_{j=1}^{n} p_{i j}} ; L O N_{i}=\frac{\sum_{j=1}^{n} p_{i j} \cdot l o n_{j}}{\sum_{j=1}^{n} p_{i j}}
$$

where $\quad p_{i j}=$ the average AOD value of city-j in i-th year

$L A, L O N_{i}=$ the coordinates of the gravity

$l a_{j}, l o n_{j}=$ the information of city-j's coordinates

2.2.3 Stepwise Multiple Linear Regression: Linear regression analysis is a statistical method to study the linear relationship between one variable and other variables. Here, we construct a linear multiple regression model to exploring the quantitative relationship between the AOD value and the independent variables.

$$
Z=a_{1} P_{1}+a_{2} P_{2}+\cdots+a_{n} P_{n}+k
$$

where $Z=$ the average AOD value

$$
P_{i}=\text { i-th factor }
$$

Stepwise regression introduces variables to the model one by one. When a new explanatory variable is introduced, the F test is carried out, and the selected explanatory variables are tested by $t$ test one by one. We will delete the original explanatory supposed that it is no longer significant due to the introduction of the later explanatory variables, and stop it until all the significant variables are selected in the regression equation, and there is no significant explanatory variable in the equation.

\section{RESUITS AND DISCUSSION}

\subsection{Spatial Autocorrelation Analysis of AOD}

3.1.1 Analysis of Global Spatial Autocorrelation: In the 
same month during 10 years, all prefecture-level cities have obvious similarities in weather and other factors. Therefore, the influence of each factor on AOD values is similar to that of AOD values, and the correlation between AOD values in the regions is strong. By calculating the ten-year Moran's I for 12 months in Jiangsu Province, it can be concluded that a positive correlation of AOD correlations exists between prefecture-level cities and most months.

As shown in Table 2, global spatial autocorrelation is not significant in March, June and October, which shows a clear climate difference between the southern region and the northern region. Besides, the "Qinling-Irrigation Canal" is an important climate dividing line in Jiangsu Province. The north of the line is characterized by a sub-humid monsoon climate while the south owns a wet subtropical monsoon climate. March is the beginning of spring, and the area in the south of the dividing line is affected by warm humid air more obviously. Under the combined influence of warm air and Siberian cold air in northern Jiangsu, the climate is unstable in this month. At the same time, a lot differences exist between the precipitation in the northern and the southern region, the average temperature, and the AOD values. In late June, the Yangtze River valley will enter the rainy season. The climate difference in regions is obvious due to precipitation and high temperature. October is a crucial period before the autumn season, for the northern region cools rapidly, while the southern region cools more slowly and is affected by the "residual" monsoon, resulting in short-term precipitation.

On the contrary, there is no significant difference between the northern and southern regions about temperature of April, September and November and the spatial autocorrelation of AOD is significant.

\begin{tabular}{|c|c|c|c|}
\hline Month & Moran's I & z-score & p-value \\
\hline Jan. & 0.2452 & 1.6869 & 0.0916 \\
Feb. & 0.2911 & 1.9256 & 0.0542 \\
Mar. & 0.0865 & 1.0205 & 0.3075 \\
Apr. & 0.4958 & 3.2861 & 0.001 \\
May & 0.2501 & 1.8313 & 0.067 \\
Jun. & 0.2233 & 1.6275 & 0.1036 \\
Jul. & 0.3744 & 2.3951 & 0.0166 \\
Aug. & 0.3651 & 2.4917 & 0.0127 \\
Sep. & 0.5949 & 3.535 & 0.0004 \\
Oct. & 0.1832 & 1.4797 & 0.139 \\
Nov. & 0.4198 & 3.0388 & 0.0024 \\
Dec. & 0.2607 & 2.1956 & 0.0281 \\
\hline
\end{tabular}

Table 2. Jiangsu Province's monthly mean Moran's I of AOD from 2007 to 2016

3.1.2 Analysis of Local Spatial Autocorrelation: The local spatial distribution of AOD is explored based on the monthly mean AOD values of ten years in each city (Figure 4 ). The values of AOD of different seasons in Jiangsu Province are different, and the factors that affect the change of AOD are also different. In spring (March, April and May), because the weather is dry and its conditions are unstable, the value of AOD shows low aggregation in the northern region and the value of AOD shows high concentration in the southern region (Figure 4). Though the monthly mean AOD in the southern region is slightly higher, the difference is not significan. Meanwhile, under the influence of cold air in Siberia, the northwest wind often affects the weather, which causes sand and dust in the northwest resulting in high AOD value. In summer, the values of AOD show different types of aggregation. Summer is also the season with the highest AOD overall as the precipitation reaches the highest. At the same time, due to the air conditioners and the hot summer weather, the AOD value is somewhat increased. However, due to an even more abundant precipitation, the monthly mean AOD in the southern region is obviously higher than that in the northern region.

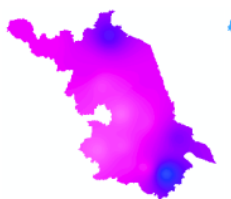

January

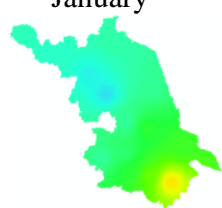

April

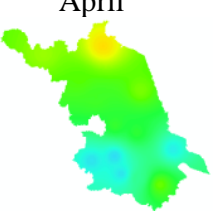

July

October

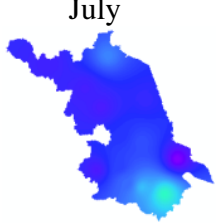

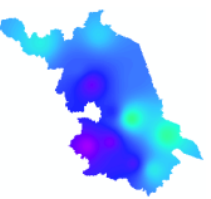

February
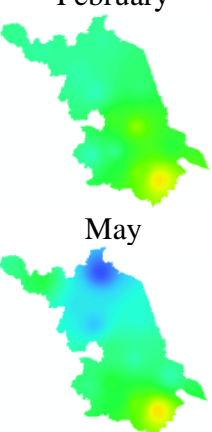

August

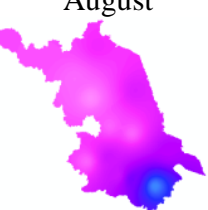

November

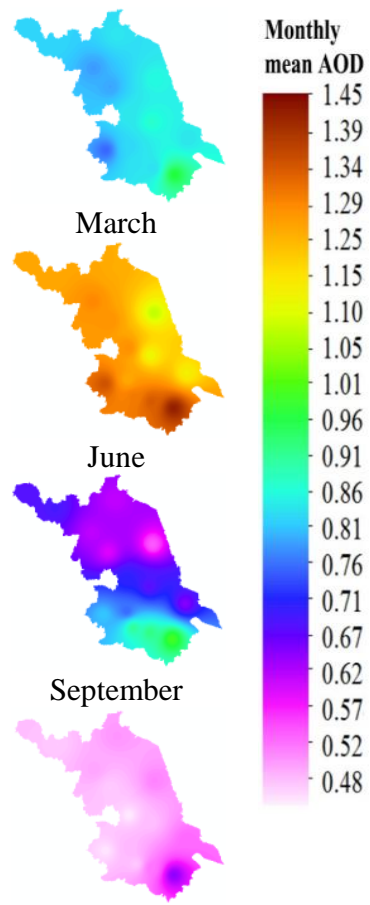

December
Figure 3. Monthly average AOD in Jiangsu Province from 2006 to 2017
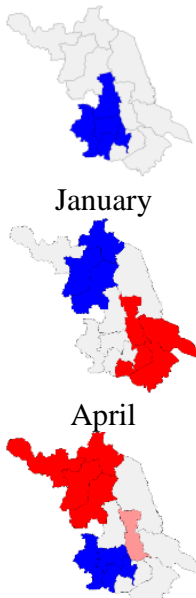

July
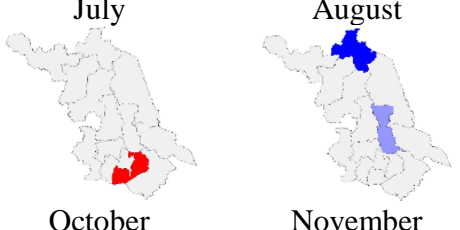

Not Significant High-High
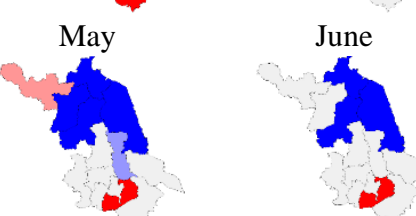

February

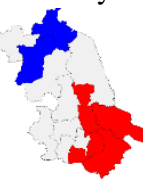

March
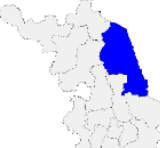

September

Figure 4. LISA map of monthly average AOD in Jiangsu Province from 2007 to 2016 
For example, the middle and lower reaches of the Yangtze River are in a hot and humid rainy season in June. The AOD values of each city reach the peak value or the next peak, which does not clearly reflect the degree of aggregation. In autumn, the AOD of all cities drop slightly, but the fall in the northern region is obvious and the fall in the southern region is narrow. Affecting by the monsoon over the ocean, the southern region shows no sudden drop in precipitation while, on the contrary, presents a rapid decline in AOD value and a phenomenon of low-level accumulation in the north. In September, there is still a large range of low-value aggregation, and there is only a small area of aggregation in October and November. In winter, the AOD value is the lowest among the whole year, but the northern region is obviously higher than the southern region. From the degree of aggregation, a large range of low value aggregates appear in the southwest region due to the heating measures in northern region of Jiangsu Province, resulting in high energy consumption of petroleum, coal and natural gas, etc. At the same time, the prevalence of northwesterly wind makes the sand dust from the northwest and the air from Northern China enter Jiangsu Province, and the influence is weakened from north to south gradually, which also causes a higher AOD general value in the north.

\subsection{Movement of AOD Gravity Center}

As shown in Figure 5, all the AOD gravity centers in the 10 years are located in Yangzhou City, which is slightly biased towards the southeast compared with Jiangsu's geometric center of gravity. In the 10 years, the AOD values in the southeast region are significantly higher than that in the northwest region, which is also consistent with the analysis earlier in this paper. the AOD gravity centers of the east-west direction are distributed with a relatively concentrated distribution, while the distribution range of the AOD gravity centers of north-south direction is large and the degree of dispersion is high. As can been seen, it shows that the AOD distribution is stable in the east-west direction, but changes greatly in the north-south direction.

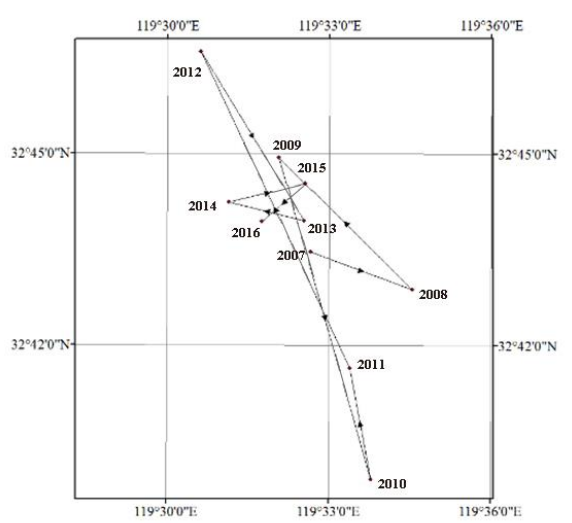

Figure 5. Migration of Jiangsu AOD gravity center

The AOD gravity centers are concentrated around $119^{\circ} 30^{\prime} \mathrm{E}$ to $119^{\circ} 33^{\prime} \mathrm{E}$ and latitude $32^{\circ} 42^{\prime} \mathrm{N}$ to $32^{\circ} 45^{\prime} \mathrm{N}$, but their changing direction are not regular. Combining the relevant meteorological data, we found that in the southern region, when the monsoon is strong and rainfall is abundant, the AOD gravity center tends to be in the southern region. For example, in 2008, a snowstorm occurred in the Yangtze River basin and the annual precipitation in southern region was significantly higher than that in normal years. As a result, the AOD gravity center was slightly southward.

\subsection{Analysis of Driving Factors}

We use the multiple linear regression method to analyse the factors affecting the AOD by stepwise regression, and we select and eliminate variables that cause multiple collinearity. After doing that, the explanatory variables that are eventually retained in the model are both important and there is no serious multiple collinearity. The method of multiple regression analysis is appropriate and reasonable for the driving factors of AOD, which is at the exploratory stage.

As shown in Table 3, eleven factors are introduced into the model. Otherwise, the production industrial solid waste and the total value of third production are eliminated by the model. The coefficient is not meaningful for the prediction of AOD since the standard regression coefficient eliminates the dimension of the original data. However, it is significant to analyze the influence of driving factors on AOD changes by the coefficient. According to Table 3, the ranking of the influence capability of the positive driving factor are VEH, PRE, TEM, NOX, SMO, GPSI, GPPI and POP. The effect of nitrogen oxide and smoke emission is the greatest. In addition, the correlation between the total number of vehicle and the total value of the second industry and AOD are the highest. In fact, these two are also the main sources of air pollution. In terms of the meteorological indicators, the influence of precipitation and temperature on AOD is the highest, the reason of which is that the combined action of warm and wet air cause the moisture absorption and expansion of water-soluble aerosol particles, and eventually lead to the increase of AOD. The area of green-land and wind power are two influencing factors that show negative influence on AOD. Plants in green-land affect the AOD greatly by immobilization of pollutants in the air. Similarly, airflow makes it impossible for the AOD to accumulate.

\begin{tabular}{|c|c|c|}
\hline Indicator & Driving Factors & $\begin{array}{c}\text { Standard Regression } \\
\text { Coefficient }\end{array}$ \\
\hline Meteorologica & TEM & 1.979 \\
1 Indicators & PRE & 2.225 \\
& WIND & -1.635 \\
Environmental & SOX & 0.375 \\
Pollution & NOX & 1.504 \\
Indicators & SMO & 1.501 \\
Socio- & POP & 0.119 \\
economic & VEH & 3.008 \\
Indicators & GPPI & 0.557 \\
& GPSI & 1.232 \\
& GREEN & -0.305 \\
\hline
\end{tabular}

Table 3. The standard regression coefficient of the variable

\section{CONCLUSION}

In this paper, we studied the spatial-temporal distribution and driving factors of AOD in Jiangsu Province from 2007 to 2016 based on the spatial autocorrelation model, gravity model and multiple regression analysis model. The annual average AOD of Jiangsu Province increases year by year. The AOD value in Jiangsu Province is along the "irrigation channel" the difference between the north and the south of the Huaihe River is obvious. It rises from spring to summer, falls from autumn and winter; the highest value appears in June, and the lowest value occurs in December. In addition, compared with urban centers, the 
AOD values in surrounding areas are relatively low, and urban centers often exhibit high-value aggregates, which are more closely related to human activities in urban centers. Through the analysis of the driving factors of AOD, we found that vehicle ownership, precipitation, temperature, and nitrogen oxides are the most important factors affecting AOD changes. Green-land and wind power will effectively reduce AOD, and the impact of wind is even more pronounced.

\section{ACKNOWLEDGEMENTS}

This study was supported by the National Science Foundation of China project (No. 41601497, No.61502246), the Natural Science Foundation of Jiangsu Province (No. BK20140868,

No. BK20170897), the NUPTSF (No. NY215181) and the SIETP(No.XZD2017098,No.XYB2017335, No.XYB2017324).

\section{REFERENCES}

Glasius,M. and Goldstein, A.,2016. Recent discoveries and future challenges in atmospheric organic chemistry.

Environmental Science \& Technology, 50(6), pp.2754-2764.

Di, Q., Kloog, I., Koutrakis, P., Lyapustin, A., Wang, Y. and Schwartz, J., 2016. Assessing PM2.5 exposures with high spatiotemporal resolution across the continental united states. Environmental Science \& Technology, 50(9), pp.4712-4721.

Lee, K. H., Man, S. W., Kim, K., and Park, S. S., 2014. Analytical approach to estimating aerosol extinction and visibility from satellite observations. Atmospheric Environment, 91(2014), pp.127-136.

Yoon, J., Pozzer, A., Chang, D. Y., Lelieveld, J., Kim, J., Kim, M., Lee,Y.G.,Koo, J.H., Lee, J.and Moon ,K.J., 2016. Trend estimates of AERONET-observed and model-simulated AOTs between 1993 and 2013. Atmospheric Environment, 125, pp.3347.

Salinas, S. V., Chew, B. N., and Liew, S. C., 2009. Retrievals of aerosol optical depth and Angstrom exponent from groundbased sun-photometer data of Singapore. Applied Optics, 48(8), pp.1473-84.

He, Q., Zhang, M., Huang, B., 2016. Spatio-temporal variation and impact factors analysis of satellite-based aerosol optical depth over China from 2002 to 2015. Atmospheric Environment, 129, pp.79-90.

Chang, T., Xiong, X., Angal, A., Wu, A., Geng, X.,2017. Aqua and Terra MODIS RSB calibration comparison using BRDF modeled reflectance. IEEE Transactions on Geoscience and Remote Sensing, 55(4), pp.2288-2298.

Taneja, K., Ahmad, S., Ahmad, K., Attri, S. D., 2016. Time series analysis of aerosol optical depth over new Delhi using Box-Jenkins ARIMA modeling approach. Atmospheric Pollution Research, 7(4), pp.585-596.

Pitoňák, M., Šprlák, Michal, Novák, P.,Tenzer, R.,2017. Regional gravity field modelling from GOCE observables. Advances in Space Research, 59(1), pp.114-127.

Crippa, P., Sullivan, R., Thota, A., Pryor, S. C.,2016. Evaluating the skill of high-resolution WRF-Chem simulations in describing drivers of aerosol direct climate forcing on the regional scale. Atmospheric Chemistry and Physics, 16(1),pp.397-416.

Revised March 2018 